Article

\title{
Cardiac Troponins are Among Targets of Doxorubicin-Induced Cardiotoxicity in hiPCS-CMs
}

\author{
Michaela Adamcova ${ }^{1, *}$, Veronika Skarkova ${ }^{2}$, Jitka Seifertova ${ }^{2}$ and Emil Rudolf ${ }^{2}$ (i) \\ 1 Department of Physiology, Faculty of Medicine in Hradec Kralove, Charles University in Prague, \\ Simkova 870, 50003 Hradec Kralove, Czech Republic \\ 2 Department of Biology, Faculty of Medicine in Hradec Kralove, Charles University in Prague, \\ Zborovská 2089, 50003 Hradec Kralove, Czech Republic; HanusovaV@lfhk.cuni.cz (V.S.); \\ seifertovaj@lfhk.cuni.cz (J.S.); rudolf@lfhk.cuni.cz (E.R.) \\ * Correspondence: adamcova@lfhk.cuni.cz; Tel.: +420-49-5816-180
}

Received: 9 April 2019; Accepted: 27 May 2019; Published: 29 May 2019

\begin{abstract}
Modern diagnostic strategies for early recognition of cancer therapeutics-related cardiac dysfunction involve cardiac troponins measurement. Still, the role of other markers of cardiotoxicity is still unclear. The present study was designed to investigate dynamics of response of human cardiomyocytes derived from induced pluripotent stem cells (hiPCS-CMs) to doxorubicin with the special emphasis on their morphological changes in relation to expression and organization of troponins. The hiPCS-CMs were treated with doxorubicin concentrations $(1$ and $0.3 \mu \mathrm{M})$ for $48 \mathrm{~h}$ and followed for next up to 6 days. Exposure of hiPCS-CMs to $1 \mu \mathrm{M}$ doxorubicininduced suppression of both cardiac troponin $\mathrm{T}$ (cTnT) and cardiac troponin I (cTnI) gene expression. Conversely, lower $0.3 \mu \mathrm{M}$ doxorubicin concentration produced no significant changes in the expression of aforementioned genes. However, the intracellular topography, arrangement, and abundance of cardiac troponin proteins markedly changed after both doxorubicin concentrations. In particular, at $48 \mathrm{~h}$ of treatment, both cTnT and cTnI bundles started to reorganize, with some of them forming compacted shapes extending outwards and protruding outside the cells. At later intervals ( $72 \mathrm{~h}$ and onwards), the whole troponin network collapsed and became highly disorganized following, to some degree, overall changes in the cellular shape. Moreover, membrane permeability of cardiomyocytes was increased, and intracellular mitochondrial network rearranged and hypofunctional. Together, our results demonstrate complex effects of clinically relevant doxorubicin concentrations on hiPCS-CM cells including changes in cTnT and cTnI, but also in other cellular compartments contributing to the overall cytotoxicity of this class of cytostatics.
\end{abstract}

Keywords: hiPCS-CMs; doxorubicin; cardiotoxicity; morphology; troponins; mitochondria

\section{Introduction}

Chemotherapy-related cardiotoxicity continues to be one of the limiting factors in the antineoplastic treatment regimens leading to a significant damage of the heart with consequent cardiac failure in treated patients [1]. One of the cytostatic drugs that is often implicated in acute as well as chronic cardiotoxicity is an anthracycline antibiotic (ANT) doxorubicin (DOX). Traditionally, the ANT (DOX)-induced cardiotoxicity and resulting chronic heart failure have been related to iron-catalyzed oxidative damage to the heart [2]. However, recently it has been suggested that the cardiotoxicity is triggered by an interaction of ANT with topoisomerase II beta (TOP2B) in cardiomyocytes [3], thereby suggesting a more complex set of mechanisms behind ANT-related toxic effects. As well as not entirely elucidated mechanisms of ANT-dependent cardiotoxicity, scientists do not thoroughly agree upon established markers of such toxicity. 
The first studies of Herman and Adamcova $[4,5]$ in the nineties describe a significant elevation of cardiac troponin $\mathrm{T}$ ( $\mathrm{cTnT}$ ) in experimental models of chronic ANT cardiotoxicity. Later, numerous experimental papers have demonstrated that ANT-induced cardiac damage is associated with a relatively prolonged release of cardiac troponins (cTns) related to the cumulative dose of ANT and that cTns are very important biochemical markers for evaluation of cardiotoxic or potentially cardioprotective effect of new agents [6-11].

A significant increase of cTns after ANT exposure has been also found in numerous clinical studies. When measured as an early biomarker of cancer cardiotoxicity, cTns rise occurs consistently in $21-40 \%$ of patients after anthracycline chemotherapy, irrespective of assay type. Though cTnI and cTnT levels are not directly comparable across the available assays, representative levels ranged from 11 to 120 $\mathrm{ng} / \mathrm{L}$ in low-dose, and 160 to more than $1900 \mathrm{ng} / \mathrm{L}$ in high-dose anthracycline regimens [12].

Moreover, many clinical studies have also demonstrated that both cTnI and cTnT indicate cardiotoxicity before any decrease in left ventricular ejection fraction (LVEF) has occurred in patients treated with ANT therapy [13]. Recently, Cardinale et al. [14] have highlighted that the use of troponins enable i) prediction of severity of future left ventricular (LV) dysfunction, because troponin $c_{\max }$ after chemotherapy correlated closely to reduction of LVEF; ii) cardiac risk stratification after chemotherapy, which allows for personalization of the intensity of cardiac monitoring; iii) better patients selection for cardioprotective therapy; iv) most patients exclusion from long-term cardiologic follow-up [15-18].

Therefore, cTns have been proposed to be a more sensitive surrogate for the detection of ANT-associated cardiotoxicity than the currently recommended method of monitoring left ventricle systolic function $[12,19,20]$. Despite lacking evidence of the particular mechanisms of cardiac cTns release, many researchers have adopted these measurements into ANT monitoring protocols and the European Society of Medical Oncology has published guidance for cTnI monitoring in patients exposed to ANT [18]. The ongoing UK multicenter Cardiac CARE study (ISRCTN24439460) aims to stratify ANT-treated patients according to high sensitivity cTnI measurement and the patients exhibiting high-risk will be randomized to cardioprotection therapy [20].

Irrespective of these guidelines and practices, several issues persist such as the question of the optimal timing of patient blood sampling. Our previous study described for the first time the diagnostic window of cTns in the development of chronic ANT cardiotoxicity, which differs significantly from acute myocardial infarction. On the well-validated model of chronic daunorubicin cardiotoxicity, the plasma levels of cTns progressively increased with the cumulative dose of chemotherapy. The significant rise occurred with a peak between $4-6 \mathrm{~h}$ and a declined until $24 \mathrm{~h}$. Discrete cTns release continued even after cessation of the therapy [21].

Still, despite the extensive research on cTns release as a biomarker of cardiotoxicity, the possible mechanisms behind cTns elevation in all clinical settings (including ischemic/reperfusion injury) have not been completely understood. Moreover, the data about the expression and morphological alterations of cTns in DOX-exposed cardiomyocytes related to their possible release are missing too. Hence, the present study was designed to investigate dynamics of acute and delayed response of human cardiomyocytes derived from human induced pluripotent stem cells (hiPSCs) to DOX. The special emphasis was placed on morphological aspects of exposed cardiomyocytes together with observations into select established DOX targets such as cTns as well as mitochondria.

\section{Results}

\section{1. iCell Cardiomyocytes Maintenance and Viability}

The hiPCS-CMs (Cellular Dynamics International, Madison, WI, USA) obtained from the frozen vials according to manufacturer's instructions showed viability of minimum $88 \%$. After their plating on fibronectin-treated surfaces of coverslips or cultivation vessels (plates) hiPCS-CMs assumed typical morphology of large adherent myocytes which gradually formed a beating monolayer with 
morphologically and spatially heterogeneous cells. The appearance and external behavior of these cells (i.e., beating) did not change during the entire experiment (up to $192 \mathrm{~h}$ of observation-Figure 1 ).

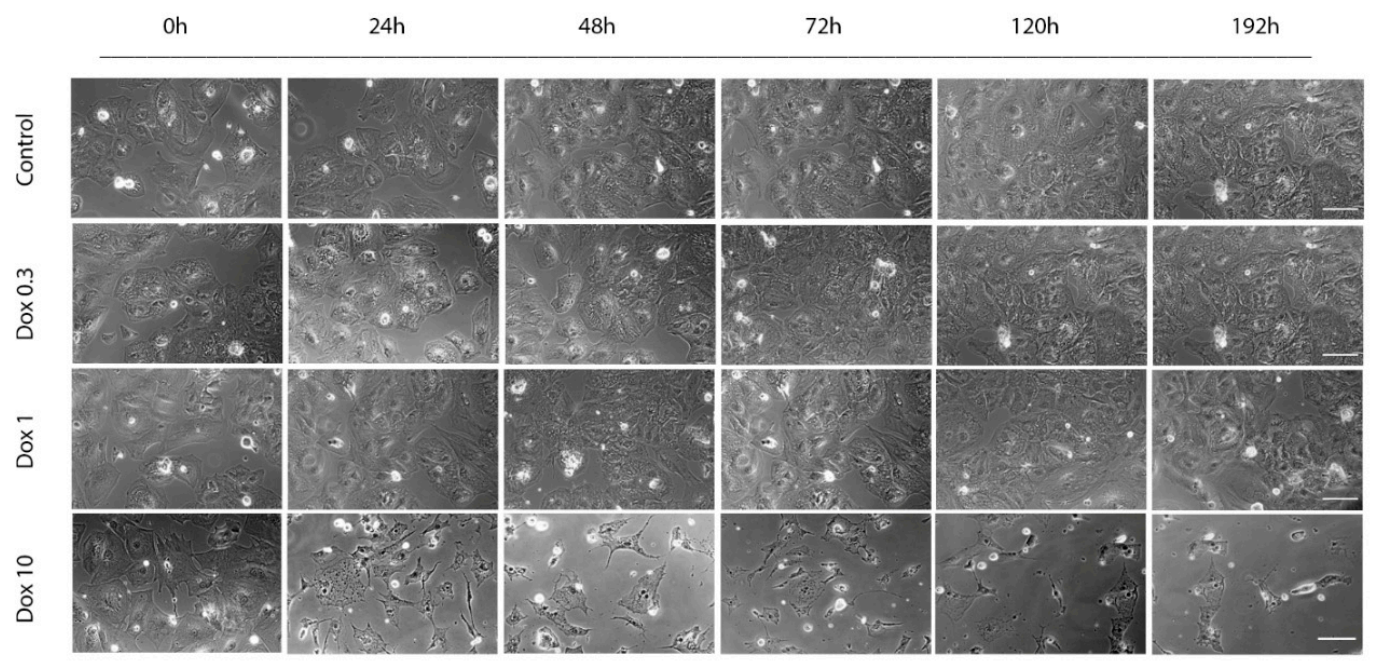

Figure 1. Time-lapse videomicroscopy of induced pluripotent stem cells (hiPCS-CMs) exposed to a range of doxorubicin (DOX) concentrations (10, 1 and $0.3 \mu \mathrm{M})$ during $192 \mathrm{~h}$. Control and DOX-exposed hiPCS-CMs cultures maintained according to the manufacturer's recommendation were continuously screened with enhanced phase contract microscopy using BioStation IM system over the mentioned time intervals. Resulting time-lapse sequences were adjusted and frame by frame analyzed using specialized software. Shown are representative morphologies of cardiomyocytes at individual time intervals. Phase contrast 400×. Bar $30 \mu \mathrm{m}$.

Viability of hiPCS-CMs in time was measured by three independent approaches; by WST-1 assay which determines the glycolytic production of $\mathrm{NAD}(\mathrm{P}) \mathrm{H}$, by neutral red (NR) assay focused on ability of viable cells to incorporate and bind the supravital dye NR in the lysosomes and by ethidium bromide assay measuring the integrity of cellular membranes. Metabolic activity of control hiPCS-CMs decreased in a time-dependent manner, with a significant drop detected at the end of the study $(192 \mathrm{~h})$ (Figure 2A). Conversely, while generally decreasing, an overall ability of cells to uptake NR and retain it within lysosomes as measured by NR content in the cells was not significantly reduced throughout the study. Similar results were obtained with ethidium bromide permeability inside the cells (Figure 2B,C).
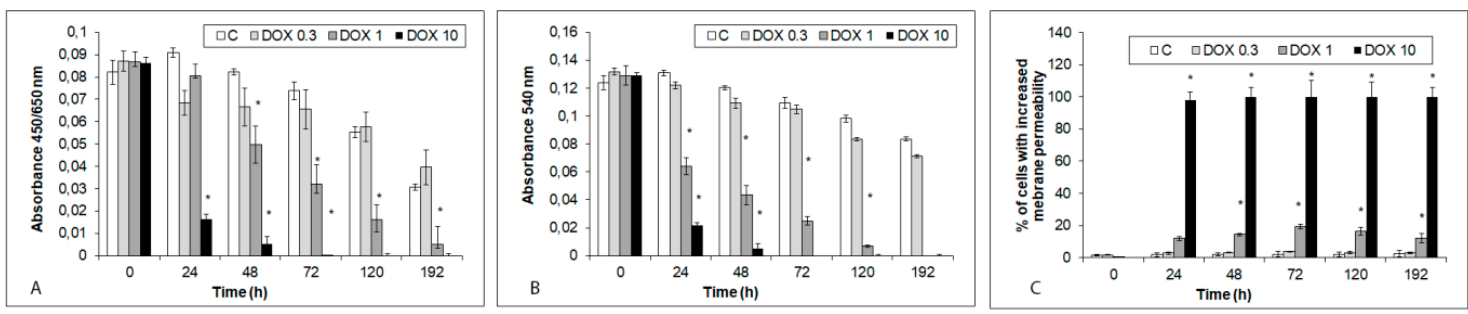

Figure 2. Effects of DOX $(10,1$ and $0.3 \mu \mathrm{M})$ on viability, metabolism and membrane permeability of hiPCS-CMs during $192 \mathrm{~h}$ has measured by WST-1, Neutral red (NR) and ethidium bromide assays as described in Materials and methods section. (A) WST-1 assay (B) NR assay (C) ethidium bromide assay. Values represent means \pm SD of at least three experiments $* p<0.05$ compared to untreated control cells at the same treatment interval with one way-Anova test and Dunnett's post test for multiple comparisons.

\subsection{Acute and Delayed Doxorubicin Effects on iCell Cardiomyocytes Morphology and Viability}

Exposure of hiPCS-CMs to DOX-induced concentration and time-dependent changes in their morphology, behavior, and viability. The highest DOX concentration of $10 \mu \mathrm{M}$ had a rather rapid and 
overwhelming effect on the cells. Already at $24 \mathrm{~h}$ of exposure most cells either lost their adherence to substratum, rounded up and became disintegrated or underwent fast intracellular degeneration which left some cells over-extended and fixed. Very few cells exhibited apoptotic morphologies-i.e., shrinkage and membrane blebbing. No further changes occurred at later time intervals and individual cells gradually fragmented. Loss of hiPCS-CMs viability and increased membrane permeability as measured by the employed assays showed corresponding dynamics; i.e., from $24 \mathrm{~h}$ of exposure onwards cells significantly stopped their metabolic activity and their membranes became fully damaged (Figure 2A-C).

Both 1 and $0.3 \mu \mathrm{M}$ DOX concentrations had less marked effects on both morphology as well as functionality of exposed cardiomyocytes as evident from their appearance and performance in the mentioned tests. Still, the extent of DOX-associated damage was concentration-dependent and the altered assay parameters appeared in varying time intervals; in case of $1 \mu \mathrm{M}$ DOX loss of viability appeared between 24 and $48 \mathrm{~h}$ of exposure and continued until the end of the experiment even after removal of DOX. Conversely, while continuously reducing cells metabolism and viability in time $0.3 \mu \mathrm{M}$ DOX-dependent cytotoxicity has never become significant at any observed time interval (Figures 1 and $2 \mathrm{~B}, \mathrm{C})$.

\subsection{Modes of iCell Cardiomyocytes Damage after Acute and Delayed Doxorubicin Exposure}

During the treatment of hiPCS-CMs with both DOX concentrations (1 and $0.3 \mu \mathrm{M})$, already at $24 \mathrm{~h}$ of exposure several types of altered cell morphologies appeared. Firstly, cells with vacuolated cytoplasm (either multiple smaller vacuoles or several larger ones-Figure 3A,B) where individual vacuoles stained positive for mitochondria (most) or autophagosomes (minority). Vacuolization developed individually in particular cells, showed varying dynamics and persisted sometimes until the end of the experiment. Alternatively, vacuolated cells at some time points shrank and underwent fragmentation. Secondly, rounded blebbing cells displaying characteristic apoptotic features peaking at $72 \mathrm{~h}$ of exposure but never comprising a significant proportion of the treated cell population (Figure 3C,D). Finally, and in most significant numbers, enlarged cells with reticular-like cytoplasm and very heterogeneous shapes and sizes. Their numbers reached maximum at $72 \mathrm{~h}$ of exposure and then they decreased $(1 \mu \mathrm{M}$ DOX) or stayed the same (0.3 $\mu \mathrm{M}$ DOX) (Figure 3E,F).
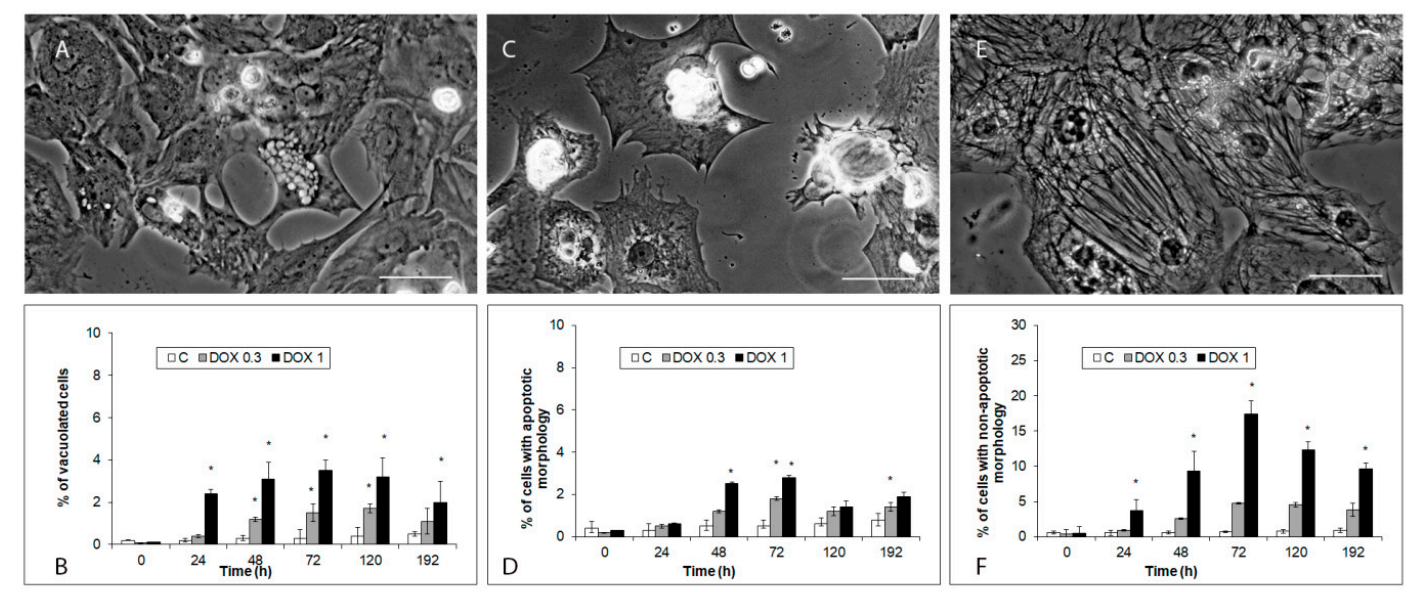

Figure 3. Effects of 1 and $0.3 \mu \mathrm{M}$ DOX on appearance of select morphologies in hiPCS-CMs cardiomyocytes during $192 \mathrm{~h}$. Cells were exposed to DOX and at individual time intervals, their morphology was examined and quantified by the Cell Scoring module of MetaXpress ${ }^{\circledR}$ Image Acquisition and Analysis Software. (A,B) Cells with vacuoles. Phase contrast 400×. Bar $10 \mu \mathrm{m} . p<0.05$ * Significantly higher than control at the same treatment interval (C,D) Blebbing cells. Phase contrast $400 \times$. Bar $10 \mu \mathrm{m} . p<0.05 *$ Significantly higher than control at the same treatment interval (E,F) Extended cells. Phase contrast 400×. Bar $10 \mu \mathrm{m} . p<0.05 *$ Significantly higher than control at the same treatment interval one way-Anova test and Dunnett's post test for multiple comparisons. 
2.4. Effects of Acute and Delayed Doxorubicin Exposure on the Expression and Organization of Troponins in iCell Cardiomyocytes

Exposure of hiPCS-CMs to $1 \mu \mathrm{M}$ DOX-induced suppression of cTnT (48 h of treatment) and cTnI gene expression ( $24 \mathrm{~h}$ and $48 \mathrm{~h}$ of exposure). Conversely, lower $0.3 \mu \mathrm{M}$ DOX concentration produced no significant changes in the expression of the aforementioned genes (Figure $4 \mathrm{~A}, \mathrm{~B}$ ).
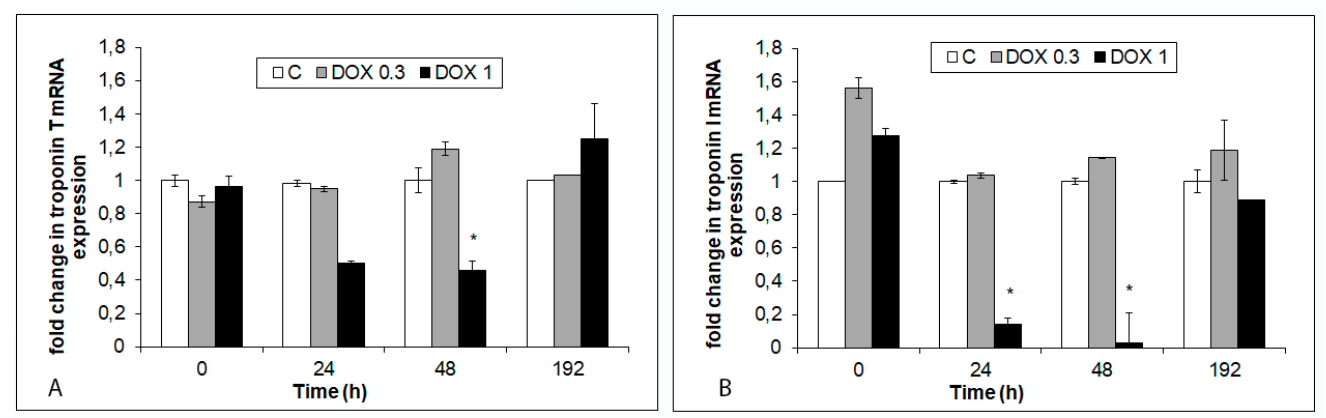

Figure 4. Effects of $0.3 \mu \mathrm{M}$ and $1 \mu \mathrm{M}$ DOX on the expression of cardiac troponin $\mathrm{T}$ and troponin I genes in hiPCS-CMs during $192 \mathrm{~h}$. Control and DOX-exposed cardiomyocytes were harvested at individual time intervals, mRNA was isolated and its quantity determined by qPCR as described in Materials and Methods. (A) Expression of troponin T. $p<0.05 *$ Significantly lower than control at the same treatment interval one way-Anova test and Dunnett's post test for multiple comparisons. (B) Expression of troponin I. $p<0.05$ * Significantly lower than control at the same treatment interval one way-Anova test and Dunnett's post test for multiple comparisons.

Unlike these differing effects of the employed DOX concentrations on cTnT and cTnI genes, the intracellular topography, arrangement and amount of these proteins markedly changed after both DOX concentrations. In particular, at $48 \mathrm{~h}$ of treatment, both cTns bundles started to reorganize, with some of them forming compacted shapes extending outwards and protruding outside the cells. At later intervals (72 $\mathrm{h}$ and onwards) whole troponin network collapsed and became highly disorganized following to some degree overall changes in the cellular shape (Figure 5).
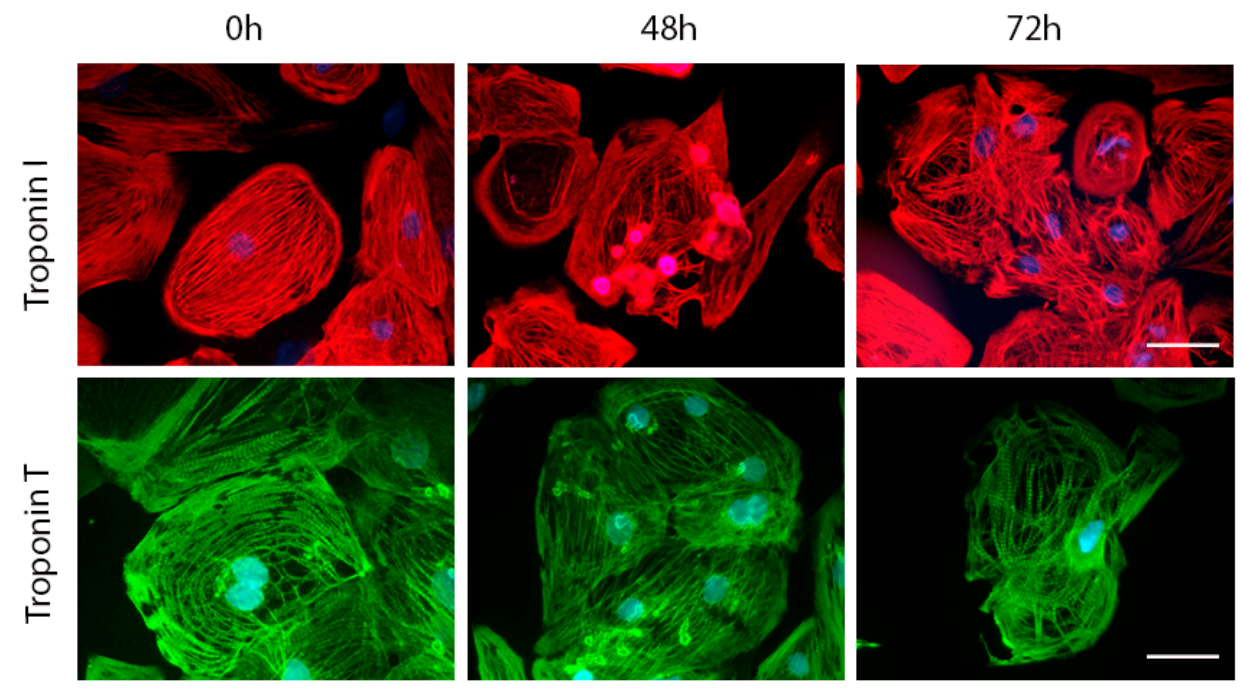

Figure 5. Effects of $1 \mu \mathrm{M}$ DOX on the localization and arrangement of troponin $\mathrm{T}$ and troponin $\mathrm{I}$ in hiPCS-CMs during $72 \mathrm{~h}$. Control and DOX-exposed cardiomyocytes were at individual time intervals rinsed with PBS, fixed, permeabilized and incubated with particular antibodies as specified in Materials and Methods section. Specimens were mounted and troponin $\mathrm{T}$ and troponin I-specific fluorescence were examined by the fluorescent microscopy and cell analysis as described in Materials and Methods. Fluorescence $400 \times$. Bar $10 \mu \mathrm{m}$. 
2.5. Effects of Acute and Delayed Doxorubicin Exposure on the Organization and Function of Mitochondria in iCell Cardiomyocytes

Control hiPCS-CMs contain long, filamentous mitochondria extending throughout the entire cytoplasm where they constantly dynamically change their position and shape. Upon treatment with DOX, this dynamics temporarily increased but from $24 \mathrm{~h}$ of exposure lessened and eventually stopped, with individual mitochondrial clusters concentrating in the perinuclear area and in or around vacuoles. Concomitant with altered morphology, mitochondrial membrane potential in hiPCS-CMs started to drop, reaching the maximum extent at $72 \mathrm{~h}$ of exposure and then again increasing but remaining reduced in significant numbers of treated cells until the end of the experiment (Figure 6).
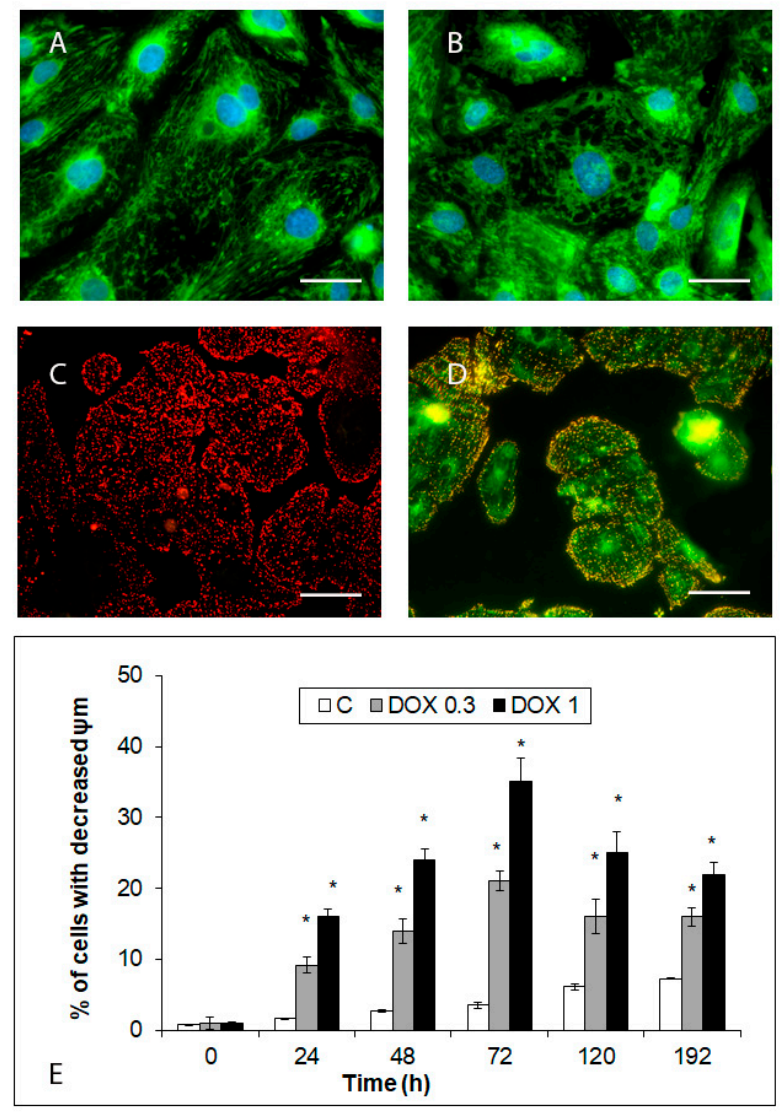

Figure 6. Effects of 1 and $0.3 \mu \mathrm{M}$ DOX on mitochondrial topography and activity in hiPCS-CMs during $192 \mathrm{~h}$. Mitochondrial morphology and arrangement in (A) control and (B) $1 \mu \mathrm{M}$ DOX-treated cells $(72 \mathrm{~h}$ ) was examined by microscopic evaluation of MitoTracker Green FM fluorescence. Mitochondrial membrane potential $(\psi)$ in $(\mathbf{C})$ control and (D) $1 \mu \mathrm{M}$ DOX-treated cells (72 h) was examined by microscopic measurement of potential-sensitive JC-1 dye. Software-aided cell quantitation of $\psi$ in 0.3 and $1 \mu \mathrm{M}$ DOX-treated cells during $192 \mathrm{~h}(\mathbf{E})$ as described in Materials and methods section. Fluorescence $400 \times(\mathbf{A}, \mathbf{B})$ and $200 \times(\mathbf{C}, \mathbf{D})$. Bars $10 \mu \mathrm{m}(\mathbf{A}, \mathbf{B}), 30 \mu \mathrm{m}(\mathbf{C}, \mathbf{D}) .{ }^{*} p<0.05$ compared to untreated control cells at the same treatment interval with one way-Anova test and Dunnett's post test for multiple comparisons.

\section{Discussion}

Current studies have demonstrated that in vitro use of human embryonic stem cell (hESC)- or (hiPSC)-derived cardiomyocytes can be beneficial for preclinical safety assessment. Recent research indicates that hiPSC-cardiomyocytes are a promising tool for evaluation of both structural and electrophysiological drug-induced cardiotoxicity [22-25] as well as for searching of new biomarkers of cardiotoxicity [26-29]. 
In the present study, hiPCS-CMs were treated with DOX concentrations of 10,1 and $0.3 \mu \mathrm{M}$ for $48 \mathrm{~h}$, with subsequent washout and monitoring for next up to 6 days to mimic both acute as well as delayed DOX toxicities. It is necessary to point out that we have used the doses of DOX, which are well within the clinical therapeutic range where the highest values of DOX $c_{\max }$ in plasma at the end of infusion are maximally $10 \mu \mathrm{M}$ [30]. Also, similar concentrations are also used in reputable laboratories worldwide [11,31].

Our results show that the high DOX concentration $(10 \mu \mathrm{M})$ induced significant changes in cardiomyocytes viability, morphology and behavior which were apparent already at $24 \mathrm{~h}$ of exposure and corresponded to fast necrotic death. Similar loss of viability with a concomitantly increased membrane permeability were observed in case of $1 \mu \mathrm{M}$ DOX treatment too albeit at a different time frame and with variable final cell morpho-phenotypes. These included vacuolated cells and cells with apoptotic or non-apoptotic morphologies. On the other hand, the lowest employed DOX concentration $(0.3 \mu \mathrm{M})$ did not significantly change previously mentioned parameters at any time interval while the same morpho-phenotypes in exposed cells were detected too. These data suggest that DOX-related cardiomyocyte damage is concentration dependent and the resulting cell phenotypes related to toxic effects of DOX are heterogeneous including their both transient and permanent appearances.

Traditionally, ANT induced cardiotoxicity has been experimentally verified via cardiomyocyte damage-dependent loss of cTns detected in the medium as an ultimate biomarker of observed cell damage $[32,33]$. Once believed to originate from cardiomyocyte necrosis, it is now suggested that multiple mechanisms contribute to the cTns release including necrosis, apoptosis, normal myocyte cell turnover, release of proteolytic cTns degradation products, increased cell-membrane permeability due to integrin-mediated "stretch" mechanisms, and formation and release of membrane blebs [34]. In our previous study isolated rat neonatal ventricular cardiomyocytes NVCM were subjected to $72 \mathrm{~h}$ treatment with $0.1 \mu \mathrm{M}, 0.3 \mu \mathrm{M}, 1 \mu \mathrm{M}$ and $3 \mu \mathrm{M}$ of daunorubicin and culture medium was sampled at $0 \mathrm{~h}, 3 \mathrm{~h}, 6 \mathrm{~h}, 12 \mathrm{~h}, 24 \mathrm{~h}, 48 \mathrm{~h}$ and $72 \mathrm{~h}$ of daunorubicin exposure for determinations of both cTnT and cTnI. The significant increase of cTns occurred at 48 and $72 \mathrm{~h}$ of ANT exposure in cardiomyocytes treated with $1 \mu \mathrm{M}$ and $3 \mu \mathrm{M}$ of ANT only [33]. Due to the complexity of mechanisms of cTns loss and with respect to our studied heterogeneous mix of exposed cardiomyocyte phenotypes, rather than focusing on mere cTns release, this study aimed to explore changes in cTns expression, topography as well as on other relevant intracellular stress events. Firstly, $1 \mu \mathrm{M}$ but not $0.3 \mu \mathrm{M}$ DOX temporarily reduced the expression of cTnT and cTnI genes in exposed cardiomyocytes. This observation is in accordance with Chaudhari et al., who showed using the GO and KEGG pathway analysis that DOX exposure preferentially suppressed the expression of genes involved in cardiac contraction and pathways related to cardiomyopathies [28]. Unlike these differential gene-specific effects, however, both DOX concentrations produced significant and lasting changes in morphology and topographical organization of $\mathrm{cTnT}$ and cTnI proteins in exposed cardiomyocytes. The most notable ones were cTns cytoplasmic rearrangements where their regular bundling patterns were replaced with a random amassment which persisted over the entire experiment. Moreover, disturbances in the cells' contractility and beating patterns occurred too. Similar alterations in DOX-treated human cardiomyocytes were reported before $[26,35]$, however, without such a detailed emphasis on morphological aspects of cTns. Thus, collectively our data indicate that morphological and likely functional changes produced by DOX in human cardiomyocytes have a lasting effect and through their persistence might contribute to their delayed malfunctioning.

It is nowadays recognized that mitochondria are among the important targets of DOX-dependent cardiomyocytes toxicity [36]. A number of studies reported acute effects of DOX on mitochondrial network structure and function associated with increased production of free oxygen and nitrogen species. In this respect, mitochondria may not only be a target of direct DOX toxicity but also contribute to the overall cell damage by inducing oxidative stress [37]. The role of mitochondrial damage in chronic (delayed) ANT-related toxicity is generally acknowledged too, with several studies reporting their employed model dependent effects of on mitochondria as well as on mitochondrial biogenesis signaling 
pathways [38-40]. Thus, is has been suggested that DOX induces fragmentation of mitochondria [41], their disorganization and functional damage [42] as well as mitochondrial enlargement and matrix disorganization [43]. The extent and permanence of such a mitochondrial damage clearly depends on the employed DOX dose too since nanomolar DOX has already been shown to cause mitochondrial disturbances [29]. Our own results confirm these observations but also show that beyond chronically disturbed mitochondrial network a significant number of followed surviving cardiomyocytes displayed reduced mitochondrial membrane potential. Although their numbers peaked at $72 \mathrm{~h}$ of exposure they were still markedly present by the end of the experiment (192 h) which seems to indicate that their recovery is a slow process and the possibility of permanent existence of such cells is real.

\section{Materials and Methods}

\subsection{Cell Cultivation, Plating, and Maintenance}

Cryovials with frozen hiPCS-CMs were thawed and carefully resuspended in plating medium according to the company's instructions. Next, viability and density of thus acquired hiPCS-CMs were determined by a trypan blue and hemocytometer (average viability rate was more than $80 \%$ ). One cryovial typically yielded a $24 \mathrm{~mL}$ suspension of viable cardiomyocytes of an average concentration of 200,000 cells/mL. Prior ( $24 \mathrm{~h}$ before) to thawing of hiPCS-CMs, sterile coverslips (diameter $12 \mathrm{~mm}$ ) were placed into individual wells of a series of 24-well cultivation plates. A working solution of fibronectin $(1 \mu \mathrm{g} / \mathrm{mL})$ was prepared from a stock solution $(1 \mathrm{mg} / \mathrm{mL})$ by addition of an adequate volume of sterile D-PBS and $600 \mu \mathrm{L}$ of this solution was added to each well. Plates with thus treated wells were incubated at $37^{\circ} \mathrm{C}$ and $5 \% \mathrm{CO}_{2}$ for $24 \mathrm{~h}$. Next day, fibronectin solution was removed from wells and immediately $600 \mu \mathrm{L}$ of prepared hiPCS-CMs suspension was pipetted to each well (the final concentration was 120,000 cells/well). Plates with seeded hiPCS-CMs were incubated at $37^{\circ} \mathrm{C}$ and $5 \% \mathrm{CO}_{2}$ for $48 \mathrm{~h}$. Next, plating medium in each well was resuspended, removed and exchanged for maintenance medium which was thereafter typically exchanged every $48 \mathrm{~h}$ as per recommendation of the producer until the end of the experiment and/or existence of the cultivation.

Alternatively, viable hiPCS-CMs were plated into 96-well plates pretreated with fibronectin as explained before (the final concentration 30,000 cells/well) and their further maintenance and treatment followed the above-mentioned protocol.

\subsection{Experimental Scheme}

The hiPCS-CMs were seeded onto coverslips in 24-well cultivation plates (or 96-well plates) according to the above-mentioned procedure. Following the $48 \mathrm{~h}$ cultivation of cells in maintenance medium, it was exchanged with fresh DOX-free maintenance medium (controls) or maintenance medium with dissolved DOX at the tested concentrations $(10,1$ and $0.3 \mu \mathrm{M})$. The iCell cardiomyocytes were exposed to DOX for $48 \mathrm{~h}$, then DOX was removed and cells in DOX-free maintenance medium were analyzed for another 6 days using several assays.

\subsection{Time-Lapse Microscopy of Cellular Morphology}

Morphology of control and doxorubicin exposed hiPCS-CMs was followed by a time-lapse imaging system BioStation IM (Nikon, Prague, Czech Republic) which recorded multiple cells at varying magnification and time-lapse modes (small as well as high for both global and detailed view of changes in behavior of treated cell populations). Recorded sequences were subsequently semi-automatically analyzed with the software NIS Elements AR 4.20 (Nikon, Prague, Czech Republic) and individual representative frames chosen for demonstration of detected trends.

\subsection{Cell Viability and Proliferation}

Control and DOX-treated hiPCS-CMs maintained in 96-well plates were at the particular time intervals washed with fresh maintenance medium (the old medium was removed). Next, cells were 
washed twice with PBS and a medium with $100 \mu \mathrm{L}$ of WST-1 $(0.3 \mathrm{mg} / \mathrm{mL})$ was added to each well. After $2 \mathrm{~h}$ of incubation $\left(37^{\circ} \mathrm{C}, 5 \% \mathrm{CO}_{2}\right)$, the absorbance was recorded by a fluorimeter SPEKTRAFluor Plus, Tecan (Salzburg, Austria) at $450 \mathrm{~nm}$ with $650 \mathrm{~nm}$ of reference wavelength. In all cases, the absorbance of the tested doxorubicin in medium alone was recorded to correct for potential inference.

In a parallel assay, control and DOX-treated hiPCS-CMs maintained in 96-well plates were at the particular time intervals stained with NR $(100 \mu \mathrm{L}$ of NR at the concentration of $80 \mu \mathrm{g} / \mathrm{mL}$ in fresh medium) and incubation at $37^{\circ} \mathrm{C}$ and $5 \% \mathrm{CO}_{2}$ continued for $3 \mathrm{~h}$. Next, the medium was removed, and cardiomyocytes were fixed in $100 \mu \mathrm{L}$ of fixative solution $\left(1 \mathrm{~g} / 100 \mathrm{~mL} \mathrm{CaCl}_{2}\right.$ in $0.5 \%$ formaldehyde) for $15 \mathrm{~min}$ in room temperature. Following the fixation, cells were washed twice with PBS and lysed in $200 \mu \mathrm{L}$ of lysis solution ( $1 \% \mathrm{CH}_{3} \mathrm{COOH}$ in $\left.50 \% \mathrm{EtOH}\right)$ for $30 \mathrm{~min}$. The number of cardiomyocytes released NR was measured by a fluorimeter SPEKTRAFluor Plus, Tecan (Salzburg, Austria) at $540 \mathrm{~nm}$.

\subsection{Fluorescent Detection of Membrane Permeability}

Control and DOX-exposed hiPCS-CMs were washed by maintenance medium and then stained with ethidium bromide $\left(100 \mathrm{nM}, 30 \mathrm{~min}, 37^{\circ} \mathrm{C}\right)$. Next, cells were rinsed in warm maintenance medium and fluorescence resulting from ethidium bromide-positive cell nuclei was in individual cells detected by the Cell Scoring module of MetaXpress ${ }^{\circledR}$ Image Acquisition and Analysis Software (Molecular Devices, LLC, Sunnyvale, CA, USA). In all experiments, on average 5000 cells (per given time interval) were included in analyses.

\subsection{Morphological Analysis of Cell Damage}

Morphologies of control and DOX-exposed hiPCS-CMs were at the specified time points analyzed the Cell Scoring module of MetaXpress ${ }^{\circledR}$ Image Acquisition and Analysis Software. In all experiments, on average 5000 cells (per given time interval) were included in analyses.

\subsection{Fluorescent Detection of Mitochondrial Membrane Potential ( $\psi m$ )}

At regular time intervals, coverslips with control and DOX-exposed hiPCS-CMs were rinsed in warm maintenance medium and stained with cationic JC- 1 dye $(10 \mu \mathrm{g} / \mathrm{mL})$ for $15 \mathrm{~min}$ at $37^{\circ} \mathrm{C}, 5 \% \mathrm{CO}_{2}$. Next, medium with JC- 1 was removed, coverslips were five times thoroughly but gently washed with warm medium and changes in mitochondrial membrane potential in individual cells were assessed by a fluorescence microscope Nikon Eclipse E 400 (Nikon, Prague, Czech Republic) using the software NIS Elements AR 3.20 for semi-quantitative image analysis.

\subsection{Fluorescent Detection of Mitochondrial Network}

At regular time intervals, coverslips with control and DOX-exposed hiPCS-CMs were rinsed in warm maintenance medium and stained with MitoTracker Green FM $\left(100 \mathrm{nM}, 30 \mathrm{~min}, 37^{\circ} \mathrm{C}\right)$ and Hoechst 33,528 $\left(10 \mathrm{nM}, 30 \mathrm{~min}, 37^{\circ} \mathrm{C}\right)$. Thereafter, medium with flurescence dyes was aspirated, coverslips were five times thoroughly but gently washed with warm medium and mounted. Mitochondrial topography in individual cells was visualized by a fluorescence microscope Nikon Eclipse E 400 (Nikon, Prague, Czech Republic) using the software NIS Elements AR 3.20 for semi-quantitative image analysis.

\subsection{Immunofluorescent Detection of Troponins}

Control and DOX-exposed hiPCS-CMs on coverslips were washed firstly by maintenance medium followed by pre-warm PBS and fixed with $4 \%$ paraformaldehyde $\left(10 \mathrm{~min}, 25^{\circ} \mathrm{C}\right)$. Next, there were rinsed with phosphate saline buffer with $1 \%$ Triton X (PBS-T), blocked in $5 \%$ BSA for $1 \mathrm{~h}$ at $25^{\circ} \mathrm{C}$ and incubated with anti-cTnT (Abcam, 1:200) and anti-cTnI (Abcam, 1:200) at $4{ }^{\circ} \mathrm{C}$ for one hour. The cells were washed 3 times with cold PBS (each $5 \mathrm{~min}, 25^{\circ} \mathrm{C}$ ) and secondary antibodies (Alexa Fluor-488/568-conjugated - 
Invitrogen-Molecular Probes, Inc., Carlsbad, CA, USA) were added for another $1 \mathrm{~h}$ incubation at $4{ }^{\circ} \mathrm{C}$. The cells were again washed 3 times in PBS (each $5 \mathrm{~min}, 25^{\circ} \mathrm{C}$ ) and then mounted into Prolong ${ }^{\circledR}$ Gold anti-fade mount with DAPI (Invitrogen-Molecular Probes, Inc., Carlsbad, CA, USA). Images were taken with a fluorescence microscope Nikon Eclipse E 400 (Nikon, Prague, Czech Republic) and NIS Elements AR software (Nikon, Prague, Czech Republic).

\subsection{Quantitative Real-Time RT-PCR Detection of Troponins Expression}

Control and DOX-exposed hiPCS-CMs from 12-well plates (150,000 cells/well/mL) were collected using TriReagent (Sigma Aldrich, Prague, Czech Republic) and total RNA was isolated using Direct-zol RNA MiniPrep kit according to manufacturer's instructions (ZymoResearch, Irvine, CA, USA). RNA yields and purity were determined measuring the absorbance at 260 and $280 \mathrm{~nm}$ using NanoDrop ND-2000 UV-Vis Spectrophotometer (Thermo Fisher Scientific, Waltham, MA, USA). Absorption ratio A260/A280 of all tested samples was greater than 1.8. The quality of RNA was checked by Agilent 2100 Bioanalyzer and the RNA integrity number (RIN) was greater than 9.0. First strand cDNA was synthesized from $1 \mu \mathrm{g}$ total RNA using RevertAid Reverse Transcriptase according to the manufacturer's instruction (Thermo Fisher Scientific, Waltham, MA, USA). After initial heat denaturation of total RNA $\left(65^{\circ} \mathrm{C}\right.$ for $\left.5 \mathrm{~min}\right)$, the reactions $(20 \mu \mathrm{L})$ were incubated for $10 \mathrm{~min}$ at $25^{\circ} \mathrm{C}$, for $50 \mathrm{~min}$ at $42^{\circ} \mathrm{C}$ and for $5 \mathrm{~min}$ at $80^{\circ} \mathrm{C}$. Obtained cDNA was diluted (5x) prior to qPCR. All cDNAs were stored at $-20^{\circ} \mathrm{C}$ until qPCR assay.

The primers for mRNA quantification were designed using Primer3. All primers were synthesized by GENERI BIOTECH (Hradec Kralove, Czech Republic). The specificity of the primers was checked by NCBI Blast tool and the reaction conditions were optimized by determining the primer concentrations. The sequences of primers were as follows: h_cTnI-F (CGTGTGGACAAGGTGGATGA), h_cTnI-R (GCCGCTTAAACTTGCCTCG), h_cTnT-F (GGAGGAGAACAGGAGGAAGG) and h_cTnT-R (CTGGATGTAACCCCCAAAATGC). The qPCR analyses were performed in Corbett RotorGene PCR Detection System using SYBR Green I detection in a final volume of $20 \mu \mathrm{L}$. The reaction mixture consisted of components from Fast Start Universal SYBR Green Master (Rox) (Roche Life Science, Mannheim, Germany) as specified by manufacturer, both forward and reverse primers (final concentrations $100 \mathrm{nM}$ ), and $10 \mu \mathrm{L}$ of diluted cDNA. The PCR reactions were initiated by the denaturation step of $10 \mathrm{~min}$ at $95^{\circ} \mathrm{C}$, followed by 40 cycles of amplification, which were performed according to the following thermo cycling profiles: denaturation for $10 \mathrm{~s}$ at $95^{\circ} \mathrm{C}$ and annealing and extension for $40 \mathrm{~s}$ at $60^{\circ} \mathrm{C}$. Fluorescence data were acquired during last step. Dissociation protocol with a gradient $\left(0.5^{\circ} \mathrm{C}\right.$ every $\left.2 \mathrm{~s}\right)$ from $65^{\circ} \mathrm{C}$ to $95^{\circ} \mathrm{C}$ was used to investigate the specificity of the qPCR reaction and presence of primer dimers. Gene-specific amplification was confirmed by a single peak in the melting curve analysis. The size of all amplicons was confirmed by $2 \%$ agarose gel electrophoresis stained with SYBR Safe DNA gel stain (Invitrogen, Waltham, MA, USA). All qPCRs were run in duplicates. Calculations were based on the "Delta-Delta Ct method". The data were expressed as fold change of the cell cultures relative to the control. Glyceraldehyde 3-phosphate dehydrogenase (GAPDH) was used as reference gene for mRNA analysis.

\subsection{Statistical Analysis}

All experiments were repeated at least three times. Data analysis was performed by GraphPad Prism (GraphPad Software version 6.0, Inc. San Diego, CA, USA). Statistical analysis was carried out using one-way analysis of variance (ANOVA) followed by Dunnett's multiple comparisons test significant at a level of $p<0.05$. In case of troponin I and T gene expression analyses two-way ANOVA with Tukey's multiple comparisons test was employed.

\section{Conclusions}

In conclusion, our results bring evidence of dose-dependent changes in the metabolism, cell membrane permeability, and cell death in human cardiomyocytes exposed acutely and chronically 
to DOX. DOX at clinically relevant concentrations temporarily downregulated the expression of cTnT and cTnI genes and induced structural and functional changes in both cTns. In addition, in thus exposed cells, chronic changes in the topography of mitochondrial network, as well as the reduction of mitochondrial membrane potential, took place, which could be responsible ultimately for the cardiomyocyte malfunction and failure.

Author Contributions: M.A.—formation of concept/design, data analysis/interpretation, writing the manuscript. V.S.- - acquisition of data, data analysis, J.S.- acquisition of data, data analysis, E.R.--formation of concept/design, acquisition of data, data analysis/interpretation, writing the manuscript.

Funding: This research received no external funding.

Acknowledgments: This work was supported by the Programme PROGRES Q 40/1 and Q 40/5. We thank M. Sterba from the Department of Pharmacology, Faculty of Medicine in Hradec Kralove, Charles University for the kind and valuable discussion of our research work.

Conflicts of Interest: The author declare no conflict of interest.

\section{References}

1. Suter, T.M.; Ewer, M.S. Cancer drugs and the heart: Importance and management. Eur. Heart J. 2013, 34, 1102-1111. [CrossRef]

2. Simunek, T.; Sterba, M.; Popelova, O.; Adamcova, M.; Hrdina, R.; Gersl, V. Anthracycline-induced cardiotoxicity: Overview of studies examining the roles of oxidative stress and free cellular iron. Pharmacol. Rep. 2009, 61, 154-171. [CrossRef]

3. Zhang, S.; Liu, X.; Bawa-Khalfe, T.; Lu, S.; Lyu, Y.L.; Liu, L.F.; Yeh, E.T. Identification of the molecular basis of doxorubicin-induced cardiotoxicity. Nat. Med. 2012, 18, 1639-1642. [CrossRef] [PubMed]

4. Herman, E.H.; Lipshultz, S.E.; Rifai, N.; Zhang, J.; Papoian, T.; Yu, Z.X.; Takeda, K.; Ferrans, V.J. Use of cardiac troponin T levels as an indicator of doxorubicin-induced cardiotoxicity. Cancer Res. 1998, 58, $195-197$.

5. Adamcová, M.; Geršl, V.; Hrdina, R.; Mělka, M.; Mazurová, Y.; Vávrová, J.; Palička, V.; Kokštein, Z. Cardiac troponin $\mathrm{T}$ as a marker of myocardial damage caused by antineoplastic drugs in rabbits. J. Cancer Res. Clin. Oncol. 1999, 125, 268-274. [CrossRef]

6. Herman, E.H.; Zhang, J.; Lipshultz, S.E.; Rifai, N.; Chadwick, D.; Takeda, K.; Yu, Z.X.; Ferrans, V.J. Correlation between serum levels of cardiac troponin- $\mathrm{T}$ and the severity of the chronic cardiomyopathy induced by doxorubicin. J. Clin. Oncol. 1999, 17, 2237-2243. [CrossRef]

7. Simunek, T.; Klimtova, I.; Kaplanova, J.; Mazurova, Y.; Adamcova, M.; Sterba, M.; Hrdina, R.; Gersl, V. Rabbit model for in vivo study of anthracycline-induced heart failure and for the evaluation of protective agents. Eur. J. Heart Fail. 2004, 6, 377-387. [CrossRef]

8. Reagan, W.J.; York, M.; Berridge, B.; Schultze, E.; Walker, D.; Pettit, S. Comparison of cardiac troponin I and $\mathrm{T}$, including the evaluation of an ultrasensitive assay, as indicators of doxorubicin-induced cardiotoxicity. Toxicol Pathol. 2013, 41, 1146-1158. [CrossRef] [PubMed]

9. Cove-Smith, L.; Woodhouse, N.; Hargreaves, A.; Kirk, J.; Smith, S.; Price, S.A.; Galvin, M.; Betts, C.J.; Brocklehurst, S.; Backen, A.; et al. An integrated characterization of serological, pathological, and functional events in doxorubicin-induced cardiotoxicity. Toxicol. Sci. 2014, 140, 3-15. [CrossRef] [PubMed]

10. Jirkovsky, E.; Lencova-Popelova, O.; Hroch, M.; Adamcova, M.; Mazurova, Y.; Vavrova, J.; Micuda, S.; Simunek, T.; Gersl, V.; Sterba, M. Early and delayed cardioprotective intervention with dexrazoxane each show different potential for prevention of chronic anthracycline cardiotoxicity in rabbits. Toxicology 2013, 311, 191-204. [CrossRef]

11. Bures, J.; Jirkovska, A.; Sestak, V.; Jansova, H.; Karabanovich, G.; Roh, J.; Sterba, M.; Simunek, T.; Kovarikova, P. Investigation of novel dexrazoxane analogue JR-311 shows significant cardioprotective effects through topoisomerase Ilbeta but not its iron chelating metabolite. Toxicology 2017, 392, 1-10. [CrossRef]

12. McGowan, J.V.; Chung, R.; Maulik, A.; Piotrowska, I.; Walker, J.M.; Yellon, D.M. Anthracycline Chemotherapy and Cardiotoxicity. Cardiovasc. Drugs Ther. 2017, 31, 63-75. [CrossRef]

13. Dolci, A.; Dominici, R.; Cardinale, D.; Sandri, M.T.; Panteghini, M. Biochemical markers for prediction of chemotherapy-induced cardiotoxicity: Systematic review of the literature and recommendations for use. Am. J. Clin. Pathol. 2008, 130, 688-695. [CrossRef] [PubMed] 
14. Cardinale, D.; Cipolla, C.M. Chemotherapy-induced cardiotoxicity: Importance of early detection. Expert Rev. Cardiovasc. Ther. 2016, 14, 1297-1299. [CrossRef] [PubMed]

15. Cardinale, D.; Sandri, M.T.; Martinoni, A.; Tricca, A.; Civelli, M.; Lamantia, G.; Cinieri, S.; Martinelli, G.; Cipolla, C.M.; Fiorentini, C. Left ventricular dysfunction predicted by early troponin I release after high dose chemotherapy. J. Am. Coll. Cardiol. 2000, 36, 517-522. [CrossRef]

16. Cardinale, D.; Sandri, M.T.; Colombo, A.; Colombo, N.; Boeri, M.; Lamantia, G.; Civelli, M.; Peccatori, F.; Martinelli, G.; Fiorentini, C.; et al. Prognostic value of troponin I in cardiac risk stratification of cancer patients undergoing high-dose chemotherapy. Circulation 2004, 109, 2749-2754. [CrossRef] [PubMed]

17. Cardinale, D.; Salvatici, M.; Sandri, M.T. Role of biomarkers in cardioncology. Clin. Chem. Lab. Med. 2011, 49, 1937-1948. [CrossRef]

18. Curigliano, G.; Cardinale, D.; Suter, T.; Plataniotis, G.; de Azambuja, E.; Sandri, M.T.; Criscitiello, C.; Goldhirsch, A.; Cipolla, C.; Roila, F. ESMO Guidelines Working Group. Cardiovascular toxicity induced by chemotherapy, targeted agents and radiotherapy: ESMO clinical practice guidelines. Ann. Oncol. 2012, 23, vii155-vii166. [CrossRef] [PubMed]

19. Cardinale, D.; Biasillo, G.; Salvatici, M.; Sandri, M.T.; Cipolla, C.M. Using biomarkers to predict and to prevent cardiotoxicity of cancer therapy. Expert Rev. Mol. Diagn. 2017, 17, 245-256. [CrossRef] [PubMed]

20. Henriksen, P.A. Anthracycline cardiotoxicity: An update on mechanisms, monitoring and prevention. Heart 2018, 104, 971-977. [CrossRef]

21. Adamcova, M.; Lencova-Popelova, O.; Jirkovsky, E.; Mazurova, Y.; Palicka, V.; Simko, F.; Gersl, V.; Sterba, M. Experimental determination of diagnostic window of cardiac troponins in the development of chronic anthracycline cardiotoxicity and estimation of its predictive value. Int. J. Cardiol. 2015, 201, 358-367. [CrossRef]

22. Abassi, Y.A.; Xi, B.; Li, N.; Ouyang, W.; Seiler, A.; Watzele, M.; Kettenhofen, R.; Bohlen, H.; Ehlich, A.; Kolossov, E.; et al. Dynamic monitoring of beating periodicity of stem cell-derived cardiomyocytes as a predictive tool for preclinical safety assessment. Br. J. Pharmacol. 2012, 165, 1424-1441. [CrossRef]

23. Pointon, A.; Abi-Gerges, N.; Cross, M.J.; Sidaway, J.E. Phenotypic profiling of structural cardiotoxins in vitro reveals dependency on multiple mechanisms of toxicity. Toxicol. Sci. 2013, 132, 317-326. [CrossRef]

24. Doherty, K.R.; Talbert, D.R.; Trusk, P.B.; Moran, D.M.; Shell, S.A.; Bacus, S. Structural and functional screening in human induced-pluripotent stem cell-derived cardiomyocytes accurately identifies cardiotoxicity of multiple drug types. Toxicol. Appl. Pharmacol. 2015, 285, 51-60. [CrossRef]

25. Burridge, P.W.; Li, Y.F.; Matsa, E.; Wu, H.; Ong, S.G.; Sharma, A.; Holmstrom, A.; Chang, A.C.; Coronado, M.J.; Ebert, A.D.; et al. Human induced pluripotent stem cell-derived cardiomyocytes recapitulate the predilection of breast cancer patients to doxorubicin-induced cardiotoxicity. Nat. Med. 2016, 22, 547-556. [CrossRef]

26. Holmgren, G.; Synnergren, J.; Bogestal, Y.; Ameen, C.; Akesson, K.; Holmgren, S.; Lindahl, A.; Sartipy, P. Identification of novel biomarkers for doxorubicin-induced toxicity in human cardiomyocytes derived from pluripotent stem cells. Toxicology 2015, 328, 102-111. [CrossRef]

27. Chaudhari, U.; Nemade, H.; Gaspar, J.A.; Hescheler, J.; Hengstler, G.; Sachinidis, A. MicroRNAs as early toxicity signatures of doxorubicin in human-induced pluripotent stem cell-derived cardiomyocytes. Arch. Toxicol. 2016, 90, 3087-3098. [CrossRef]

28. Chaudhari, U.; Nemade, H.; Wagh, V.; Gaspar, J.A.; Ellis, J.K.; Srinivasan, S.P.; Spitkovski, D.; Nguemo, F.; Louisse, J.; Bremer, S.; et al. Identification of genomic biomarkers for anthracycline-induced cardiotoxicity in human iPSC-derived cardiomyocytes: An in vitro repeated exposure toxicity approach for safety assessment. Arch. Toxicol. 2016, 90, 2763-2777. [CrossRef]

29. Louisse, J.; Wust, R.C.I.; Pistollato, F.; Palosaari, T.; Barilari, M.; Macko, P.; Bremer, S.; Prieto, P. Assessment of acute and chronic toxicity of doxorubicin in human induced pluripotent stem cell-derived cardiomyocytes. Toxicol. In Vitro 2017, 42, 182-190. [CrossRef]

30. Balis, F.M.; Holcenberg, J.S.; Bleyer, W.A. Clinical pharmacokinetics of commonly used anticancer drugs. Clin. Pharmacokinet. 1983, 8, 202-232. [CrossRef]

31. Hasinoff, B.B.; Patel, D.; Wu, X. Molecular Mechanisms of the Cardiotoxicity of the Proteasomal-Targeted Drugs Bortezomib and Carfilzomib. Cardiovasc. Toxicol. 2017, 17, 237-250. [CrossRef]

32. Andersson, H.; Steel, D.; Asp, J.; Dahlenborg, K.; Jonsson, M.; Jeppsson, A.; Lindahl, A.; Kagedal, B.; Sartipy, P.; Mandenius, C.F. Assaying cardiac biomarkers for toxicity testing using biosensing and cardiomyocytes derived from human embryonic stem cells. J. Biotechnol. 2010, 150, 175-181. [CrossRef] 
33. Adamcova, M.; Simunek, T.; Kaiserova, H.; Popelova, O.; Sterba, M.; Potacova, A.; Vavrova, J.; Malakova, J.; Gersl, V. In vitro and in vivo examination of cardiac troponins as biochemical markers of drug-induced cardiotoxicity. Toxicology 2007, 237, 218-228. [CrossRef]

34. White, H.D. Pathobiology of troponin elevations: Do elevations occur with myocardial ischemia as well as necrosis? J. Am. Coll. Cardiol. 2011, 57, 2406-2408. [CrossRef]

35. Kopljar, I.; De Bondt, A.; Vinken, P.; Teisman, A.; Damiano, B.; Goeminne, N.; Van den Wyngaert, I.; Gallacher, D.J.; Lu, H.R. Chronic drug-induced effects on contractile motion properties and cardiac biomarkers in human induced pluripotent stem cell-derived cardiomyocytes. Br. J. Pharmacol. 2017, 174, 3766-3779. [CrossRef]

36. Zhang, Y.W.; Shi, J.; Li, J.Y.; Wei, L. Cardiomyocyte death in doxorubicin-induced cardiotoxicity. Arch. Immunol. Ther. Exp. 2009, 57, 435-445. [CrossRef]

37. Koleini, N.; Kardami, E. Autophagy and mitophagy in the context of doxorubicin-induced cardiotoxicity. Oncotarget 2017, 8, 46663-46680. [CrossRef]

38. Zhou, S.; Starkov, A.; Froberg, M.K.; Leino, R.L.; Wallace, K.B. Cumulative and irreversible cardiac mitochondrial dysfunction induced by doxorubicin. Cancer Res. 2001, 61, 771-777.

39. Carvalho, F.S.; Burgeiro, A.; Garcia, R.; Moreno, A.J.; Carvalho, R.A.; Oliveira, P.J. Doxorubicin-induced cardiotoxicity: From bioenergetic failure and cell death to cardiomyopathy. Med. Res. Rev. 2014, 34, 106-135. [CrossRef]

40. De Oliveira, B.L.; Niederer, S.A. Biophysical Systems Approach to Identifying the Pathways of Acute and Chronic Doxorubicin Mitochondrial Cardiotoxicity. PLoS Comput. Biol. 2016, 12, e1005214. [CrossRef]

41. Parra, V.; Eisner, V.; Chiong, M.; Criollo, A.; Moraga, F.; Garcia, A.; Hartel, S.; Jaimovich, E.; Zorzano, A.; Hidalgo, C.; et al. Changes in mitochondrial dynamics during ceramide-induced cardiomyocyte early apoptosis. Cardiovasc. Res. 2008, 77, 387-397. [CrossRef]

42. Lebrecht, D.; Kokkori, A.; Ketelsen, U.P.; Setzer, B.; Walker, U.A. Tissue-specific mtDNA lesions and radical-associated mitochondrial dysfunction in human hearts exposed to doxorubicin. J. Pathol. 2005, 207, 436-444. [CrossRef]

43. Sardao, V.A.; Oliveira, P.J.; Holy, J.; Oliveira, C.R.; Wallace, K.B. Morphological alterations induced by doxorubicin on H9c2 myoblasts: Nuclear, mitochondrial, and cytoskeletal targets. Cell. Biol. Toxicol. 2009, 25, 227-243. [CrossRef] [PubMed] 